\title{
Study of physio-psychological effects on traffic wardens due to traffic noise pollution; exposure-effect relation
}

\author{
Shamas Tabraiz ${ }^{1 *}$, Saeed Ahmad ${ }^{1}$, Iffat Shehzadi ${ }^{2}$ and Muhammad Bilal Asif ${ }^{1}$
}

\begin{abstract}
Background: Noise pollution has increased to alarming extent in most of the urban areas in Pakistan. It is assumed even more perilous than air and water pollution due to its direct acute and chronic physio-psychological effects. The objective of this study is to analyze and evaluate the psychological and physiological effects caused by traffic noise on traffic wardens and to find relation type between exposure time and effect.

Methods: Three wardens check posts near roads were selected for survey in Taxila and Islamabad cities of Pakistan. Survey conducted included noise measurements at aforementioned check posts for one month and Performa based interviews of traffic wardens.

Results and conclusions: Analysis of results showed that noise levels varied between 85-106 dB hence violating OSHA regulations. Major psychological effects found in wardens were aggravated depression 58\%, stress 65\%, public conflict $71 \%$, irritation and annoyance $54 \%$, behavioral affects $59 \%$ and speech interference $56 \%$. Physiological effects found were hypertension $87 \%$, muscle tension $64 \%$, exhaustion $48 \%$, low performance levels $55 \%$, concentration loss $93 \%$, hearing impairment $69 \%$, headache $74 \%$ and cardiovascular issue $71 \%$. Relation between exposure time and effects were evaluated by using simple regression test in excel. Percentage of psychological and physiological effects in wardens varied with the exposure time; aggravated depression $\left(R^{2}=0.946, P=0.133\right)$, stress suffering $\left(R^{2}=0.014, P=0.173\right)$, public conflict $\left(R^{2}=0.946, P=0.133\right)$, irritation and annoyance $\left(R^{2}=0.371, P=0.137\right)$, behavioral affects $\left(R^{2}=0.596, P=0.0616\right)$ and speech interference $\left(R^{2}=0.355, P=0.445\right)$, hypertension $\left(R^{2}=0.96, P=0.00095\right)$ and cardiovascular issue $\left(R^{2}=0.775, P=0.044\right)$.
\end{abstract}

Keywords: Noise pollution, Traffic wardens, Physio-psychological effects, Exposure-effect relation

\section{Introduction}

Economical and social structure of society has been changed in Pakistan due to rapid population increase, urbanization and industrialization. Due to advancement in transportation facilities and technology the traffic loads are increasing at an alarming rate which initiates a major problem of noise pollution. Noise is an unwanted sound which has different frequencies and acoustic pressure without any regular pattern. The major causes of noise pollution are roads, railway and air traffic. Characteristics of noise (frequency and acoustic pressure) depend upon the characteristics of the traffic and road i.e.

\footnotetext{
* Correspondence: shamastabraiz28@yahoo.com

${ }^{1}$ Department of Environmental Engineering, University of Engineering \&

Technology, Taxila, Pakistan

Full list of author information is available at the end of the article
}

road gradient, road surface type, surrounding topography, grade of road, number of vehicles, type of vehicles, ages of vehicle passing, speed of vehicles, type of goods transported, packing of goods in vehicles, horns sound pressure, meteorological conditions, type of breaks and behavior of the drivers. Most effective way of controlling noise is to reduce it at source i.e. vehicle and road. Noise contribution from different parts of vehicles is different; Air intake system 9\%, exhaust system 27\%, tires $30 \%$ and engine $34 \%$. At $70 \mathrm{~km} / \mathrm{h}$ speed the tire noise dominate on other sources within the vehicle. Therefore, limiting the vehicle speed on busy roads substantially reduces noise the level [1]. Only $5 \%$ reduction in the gradient of road reduces $1.5 \mathrm{~dB}$ of Leq noise. Road surface macro-texture wavelength range should be $2-10-20 \mathrm{~mm}$ to reduce noise levels. Similarly, Green belts, plants and 
trees along the roads are effective in the reduction of noise levels. For $10 \mathrm{~dB}$ reduction, mounds and barriers along the roads are suggested to construct. Building treatment is also effective for the reduction of internal noise i.e. single glazed and double glazed windows reduce 10 and $25 \mathrm{~dB}$ noise level, respectively [2]. Management of noise is important to shun its perilous effects. High noise levels deteriorate the health of people and thus subjected to economy loss.

Access to pollution free environment is the central theme of human rights. Therefore, it should be everybody's task to keep ambient environment natural and clean as much as possible [3]. Noise is discarded, unlikable and annoying sound of such duration, intensity or other quality that can cause any kind of physiological harm to human health or other living things [4]. Traffic noise is a source of annoyance [5-7]. It is detrimental to the health of every third person. Every one out of five persons in Europe is exposed to health deteriorating noise levels even at night (WHO). Noise has identified as one of the main environmental problem in Europe but lower priority is given to it as compared to water and air pollution [8]. A study was carried out on healthy individuals who migrated to the high and low noise levels residential areas of Bonn city. The blood pressure got to higher level in the individuals who moved to higher noise level areas as compared to those who moved in quitter areas [9]. Another study revealed that blood pressure quickly returned to normal when elevated noise came to lower level. Relationship between the noise levels and sleep quality is complex. It is recommended by World Health Organization that noise level in the bed room should be kept below the average level of $30 \mathrm{~dB}$, or maximum of $45 \mathrm{~dB}$ for a single event. Higher levels of sound are related to reduced sleeping quality or awakening.

Cardiovascular effects due to traffic noise exposure are an important area of research in environmental epidemiology. Adverse health effects of noise like blood pressure and hypertension were studied. Noise level and blood pressure relationship found in both children and adults was inconsistent $[10,11]$. Rather, more consistent results have been obtained in case of hypertension, with aircraft noise as well as road traffic noise [12-22]. Relationship between exposure to traffic noise and hearing impairment, ischemic heart disease, hypertension, annoyance and sleep disturbance was established [23]. In the recent years the cause relationship between traffic noise and cardiovascular risk has been increased [24]. Impacts of noise pollution include but not limited to the impairment of mind-peace, internal peace, impairment of hearing and the physiological impacts [25]. Noise pollution could impair physiological and psychological aspects of human health [26]. The effects of long term exposure are not well understood. Long term effects are linked to hypertension and heart diseases [8]. Traffic wardens in the cities are mostly appointed on the traffic rush junctions of the roads to regulate the traffic. Therefore, they are exposed to elevated noise levels. Long term physiopsychological effects of traffic noise on traffic wardens and effects relation with exposure time has not been evaluated yet. Therefore, this study was undertaken with these objectives. Beside that Noise levels were also measured at three wardens check posts situated along the Grand Truck Road (Taxila, Islamabad).

\section{Materials and methods}

The study was divided in two phases. In the first phase, noise levels were measured. In second phase, physiopsychological effects were evaluated.

\section{Exposure assessment}

Three wardens check posts along the Grand Truck Road were selected for noise survey in Taxila and Islamabad. The check posts selected were Taxila underpass check post, Tarnol check post and Golra mor check post. These check posts were selected keeping in view the movement of crush and other goods carrying heavy vehicles. The measurements were taken at those points where the traffic wardens were found to be performing their duties. Usually they perform their duties within 1-5-10 $\mathrm{m}$ range from the road side. Noise monitoring was conducted for one month. The noise level meter during measurements was held at a height of 1.5 meter above ground level at an angle of $30^{\circ}$ from monitoring persons' body, to measure noise levels which can be perceived by the human ears. A one minute reading time was set at each location in order to obtain a stable maximum reading of noise at that particular location. In this way, 60 readings were noted at every location for an hour, each one after 1 minute then the Leq ( 8 hrs) for the day was calculated.

\section{Physio- psychological effects assessment}

In the second phase, a wide-ranging standardized questionnaire was developed. It took 30-40 minute to interview a warden. Wardens appointed at the aforementioned three and nearby check posts were interviewed. The questionnaire covered housing (socio-economic conditions), exposure, heritage physio-psychological diseases, any accidental disability or psycho effect, age, working exposure, medication of any physio-psycho disease. The psychological effects evaluated were; aggravated depression, stress, public conflict, irritation and annoyance, behavioral effects and speech interference. The psychological effects were judged and evaluated on the basis of questions asked verbally: "Did you have aggravated depression? (Yes, no)", "Did any one of your parents have aggravated depression? 
(Yes, no)", "Did you have aggravated depression before joining the job as traffic warden? (Yes, no)", "Did you ever take anti-depressive medicine? (Yes, No)". Same types of questions were asked to assess other psychological effects. The physiological effects evaluated were; hypertension, muscle tension, exhaustion, exasperated fatigue, low performance levels, concentration loss, earache, hearing impairment, headache, cardiovascular issue, tinnitus and insomnia. The effects like muscle tension, exhaustion, exasperated fatigue, low performance levels, concentration loss, earache, headache, tinnitus and insomnia were evaluated with 7- grade verbal question; "Did you have hypertension? (Yes, no)", "Did one of your parents have hypertension? (Yes, no)", "Did you have hypertension before joining the job as traffic warden? (Yes, no)", "Did you ever take anti-hypertensive medicine? (Yes, no)", "Do you feel muscle tension during or after job hours? (Often, sometime, seldom or never)", "Is there any reason of muscle tension other than noise at your job place? (Yes, no)", if "Yes" then what? Same types of questions were asked to evaluate the effects like exhaustion, exasperated fatigue, low performance levels and concentration loss. For earache and headache; "Do you feel earache and headache due to high noise levels? (Often, sometime, seldom or never)", "Do you ever got injury in head or ear? (Yes, no)". For hearing impairment; "Do you have hearing impairment? (Yes, no)", "Was there an accident which impaired your hearing? (Yes, no)". For insomnia and tinnitus; "Do you have any sleeping problem (early wakeup, falling asleep, awakening)?: (often, sometime, seldom or never)" [27], "Do you have tinnitus problem (ear ringing)? (often, sometime, seldom or never)". For the cardiovascular problem; "Do you have any cardiovascular issue (valve problem, ischemic stroke, heart failure)? (Yes, no)". If yes, do you have heart problem before the joining of job? (Yes, no), "Are you taking any medication? (Yes, no)". All the wardens were divided into different groups based on the job experience (exposure time); group A (1-5 years), Group B (5-10 years), Group C (10-15 years) and Group D (15-20 years). After the assessment of exposure and physiopsychological effects, the simple linear regression was applied by using Microsoft excel to estimate the association of exposure time with physio-psychological effects. Two hundred and fifty wardens were interviewed to evaluate the effects.

\section{Results and discussions}

\section{Noise levels}

Noise level measurements were taken at selected locations near the check posts. Noise levels (Leq for 8 hours) of three check posts at $1 \mathrm{~m}, 5 \mathrm{~m}$ and $10 \mathrm{~m}$ distance from road are given below in Figures 1, 2 and 3. Noise levels (Leq) varied from 86-106 dB. Such high levels were due to the heavy traffic and high pressure horns. Impulsive noise levels measured were up to $120 \mathrm{~dB}$. Even at the distance of $10 \mathrm{~m}$ noise levels (Leq) did not dropped below $85 \mathrm{~dB}$. At the distance of $10 \mathrm{~m}$, noise levels range was $85-95 \mathrm{~dB}$, at all the selected posts. While at the distance of $5 \mathrm{~m}$ from road, noise levels (Leq) measured were in the range 88-102 dB, at all the selected point. At $1 \mathrm{~m}$ away from road, noise levels (Leq) range was 91-106 $\mathrm{dB}$. Hearing impairment could be possible of such high noise pressure level (120 dB), even for short period (seconds) exposure. From the measurements, it was assessed that not only the wardens performing duty but people living near roads are under severe threat of possible physiological as well psychological effects.

\section{Psychological effects}

The common psychological effects i.e. hypertension, aggravated depression, stress, public conflict, irritation and annoyance, behavioral effects and speech interference were taken into account for this study. All the results of

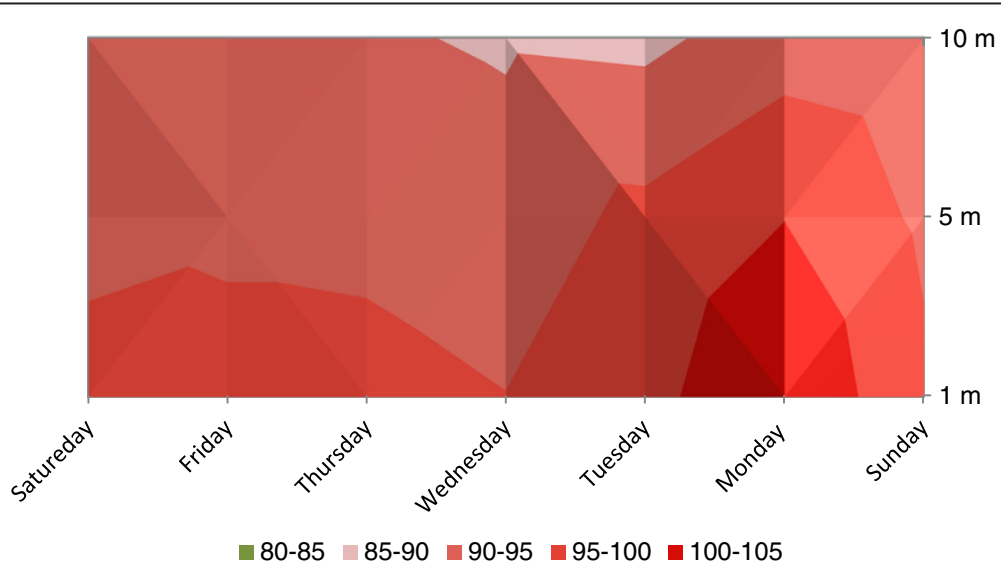

Figure 1 Noise levels (Leq 8hrs) at Taxila Underpass check post. 


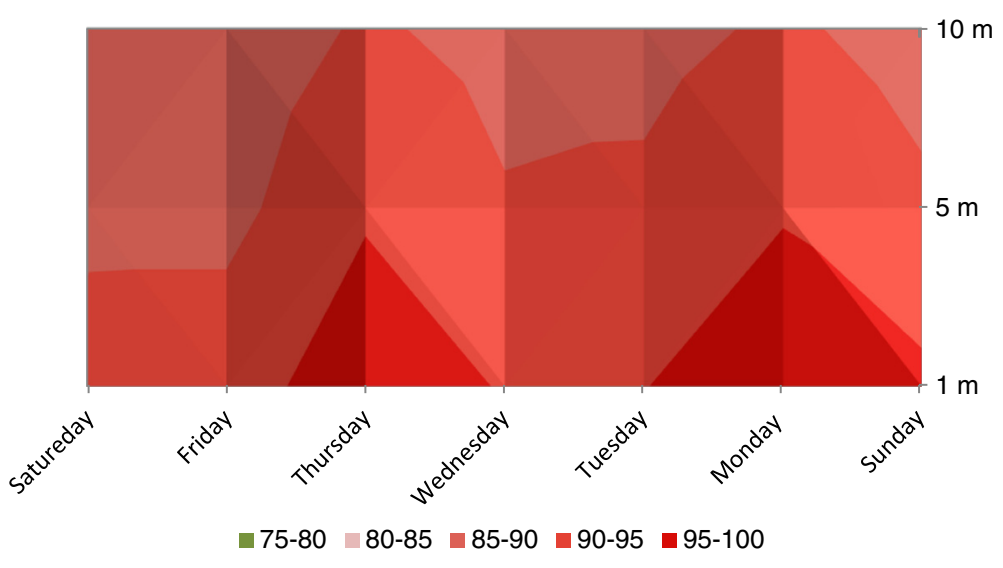

Figure 2 Noise levels (Leq 8hrs) Tarnol check post.

psychological effects are explained below and shown in Figures 4 and 5.

\section{Aggravated depression}

In aggravated depression one feels sadness, hopelessness and loss of interest in life. The survey study statistics showed that $58 \%$ of the wardens were suffering from aggravated depression. Exposure time wise, there was variance in effected warden's percentage. Aggravated depression found; $35 \%, 54 \%, 62 \%$ and $80 \%$ in group A, B, C and D, respectively. A linear relation was found between exposure time and the percentage of aggravated depression suffering wardens $\left(R^{2}=0.978, P=0.033\right)$.

\section{Stress}

In case of stress, $65 \%$ of the wardens of all the groups were suffering from stress. Exposure wise trend was random. Group A, B, C \& D reported 60\%, 70\%, 50\% and $80 \%$ stress, respectively. A non-linear relation was found between the exposure time and wardens percentage of stress suffering $\left(R^{2}=0.16, P=0.093\right)$.

\section{Public conflict}

Public conflict evaluated was $71 \%$. It showed random trend as the exposure time increased. $70 \%, 69 \%, 45 \%$ and $100 \%$ public conflict problem found for group A, B, C and $D$ group, respectively. A non-linear relation was found between exposure time and the percentage of wardens reported public conflict often $\left(R^{2}=0.143, P=0.223\right)$.

\section{Irritation and annoyance}

Irritation and annoyance was found in 54\% wardens. Exposure time wise percentage suffering from irritation and annoyance was; $40 \%, 65 \%, 50 \%$ and $62 \%$ in group A, $\mathrm{B}, \mathrm{C}$ and $\mathrm{D}$, respectively. A non linear relationship was found between exposure time and percentage of wardens suffered irritation and annoyance $\left(R^{2}=0.327, P=0.099\right)$.

\section{Behavioral effects}

Behavior changes were reported by $59 \%$ wardens. Exposure time wise behavioral effects reported were $70 \%, 81 \%$, $59 \%$ and $25 \%$ in group A, B, C and D, respectively. Percentage effected showed a linear relation with exposure

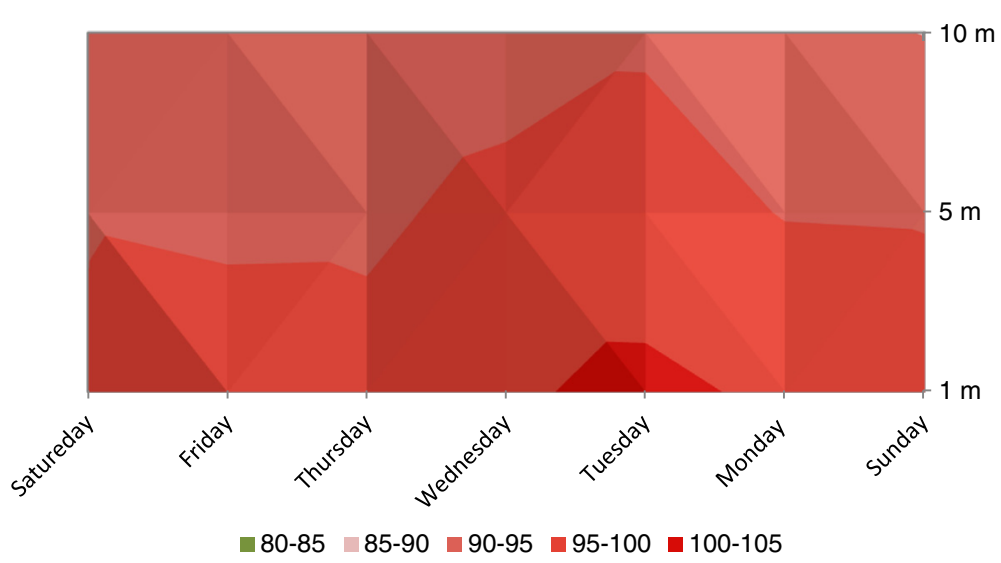

Figure 3 Noise levels (Leq 8hrs) Golra mor check post. 


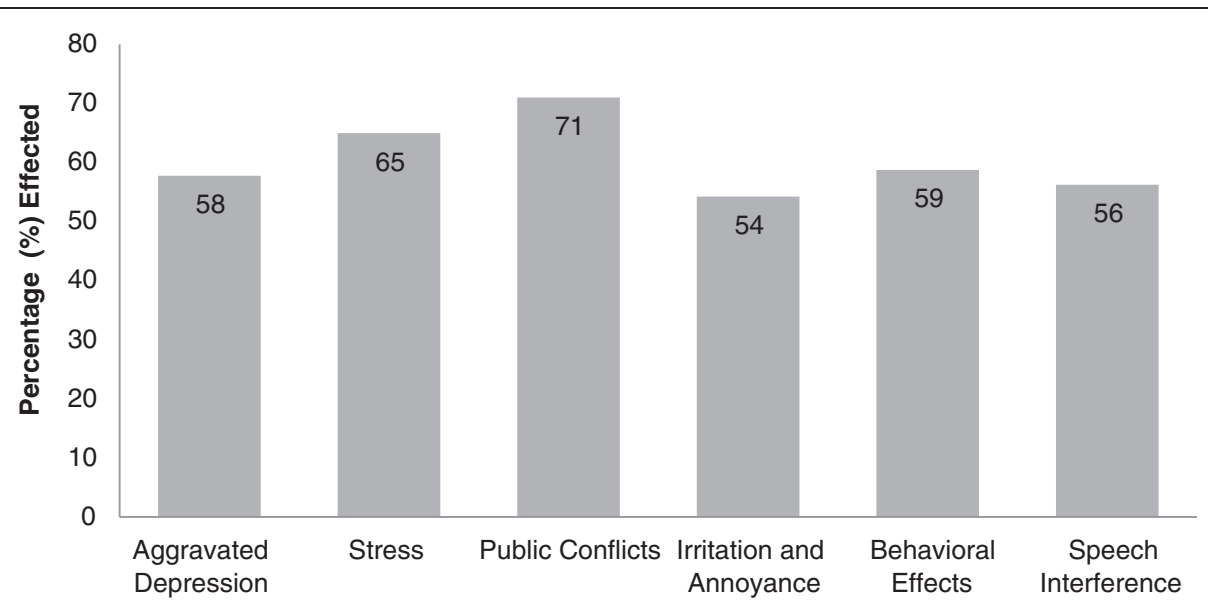

Figure 4 Psychological effects of noise on traffic wardens.

time $\left(R^{2}=0.7, P=0.0388\right)$. Results showed that percentage increased initially from 1-10 years of exposure then decreased afterward.

\section{Speech interference}

$56 \%$ of the surveyed wardens reported that noise create difficulty in conversation. Exposure time wise percentage of wardens' reported speech interference was; $40 \%, 40 \%$, $85 \%$ and $60 \%$ in group A, B, C and D, respectively. A non-linear relation was established between exposure time and the percentage of wardens reported speech interference $\left(\mathrm{R}^{2}=0.4, \mathrm{P}=0.349\right)$.

\section{Physiological effects}

In Figure 6, physiological effects that were investigated in this study for traffic wardens are given. Hypertension, muscle tension, exhaustion, exasperated fatigue, low performance levels, concentration loss, earache, hearing impairment, headache, cardiovascular issue, tinnitus and insomnia were probed. All the results of physiological effects are briefly discussed below and shown in Figure 6. Exposure time wise effects are shown in Figures 7 and 8.

\section{Hypertension}

In the survey $87 \%$ of the wardens were found to be suffering from hypertension (high blood pressures). The effected personnel percentile variation with the exposure time was as: in group A; $79 \%$, group B; $82 \%$, group C; $91 \%$ and group D; $94 \%$. A linear trend was found between the exposure time and hypertension in the wardens $\left(R^{2}=0.976, P=0.001\right)$.

\section{Muscle tension}

Muscle tension reported was 64\%. Exposure time wise muscle tension reported by group A, B, C and D were $52 \%, 55 \%, 71 \%$ and $80 \%$, respectively. It increased as the exposure time increased. A linear relation was found between wardens' percentage affected and exposure time $\left(R^{2}=0.945, P=0.0136\right)$.

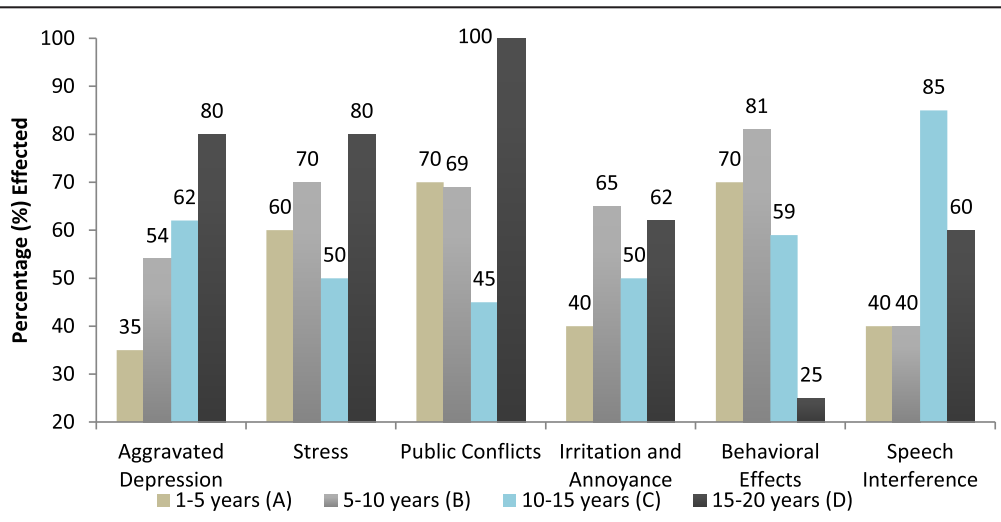

Figure $\mathbf{5}$ Exposure time wise psychological effects of noise on traffic wardens. 


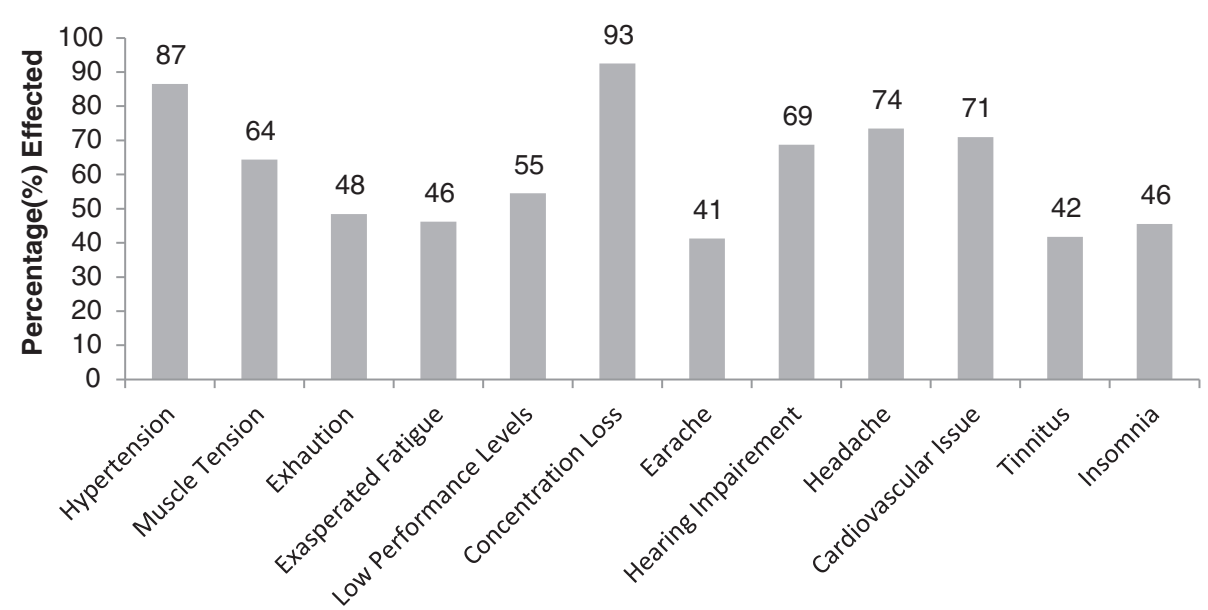

Figure 6 Physiological effects of noise on traffic wardens.

\section{Exhaustion}

Survey results showed that $48 \%$ wardens were suffering from exhaustion. Exposure time wise exhaustion in group A, B, C and D was 55\%, 64\%, 38\% and 37\%, respectively. Percentage effected showed a little linear relation with exposure time $\left(R^{2}=0.609, P=0.0312\right)$. Results showed that percentage reported exhaustion increased initially from 1-10 years of exposure then decreased afterward.

\section{Exasperated fatigue}

"Noise does exasperated fatigue" reported by $46 \%$ wardens. Exasperated fatigue found as 35, 65, 62 and 23\% in group $\mathrm{A}, \mathrm{B}, \mathrm{C}$ and $\mathrm{D}$, respectively. Percentage reported exasperated fatigue showed a non-linear relation with exposure time $\left(\mathrm{R}^{2}=0.06, \mathrm{P}=0.201\right)$. Results showed that percentage increased initially from 1-15 years of exposure then decreased afterward up to 20 years exposure.

\section{Low performance levels}

"Elevated noise levels reduce the performance levels" reported by $55 \%$ traffic wardens. Group A, B, C and D were suffering low performance level; 40\%, 56\%, 62\% and $60 \%$, correspondingly. With the increase in exposure time the percentage effected increased. It showed linear relation $\left(R^{2}=0.728, P=0.0396\right)$ between exposure time and percentage of effected wardens.

\section{Concentration loss}

Elevated noise caused concentration loss, 93\% wardens reported. Exposure time wise concentration loss reported was $70 \%, 100 \%, 100 \%$ and $100 \%$ in group A, B, $\mathrm{C}$ and D, respectively. After 5 years of exposure $100 \%$ personnel reported concentration loss due to noise. It showed approximately constant relation after 5 years $\left(\mathrm{R}^{2}=0.6, \mathrm{P}=0.0389\right)$ between exposure time and percentage of effected wardens.

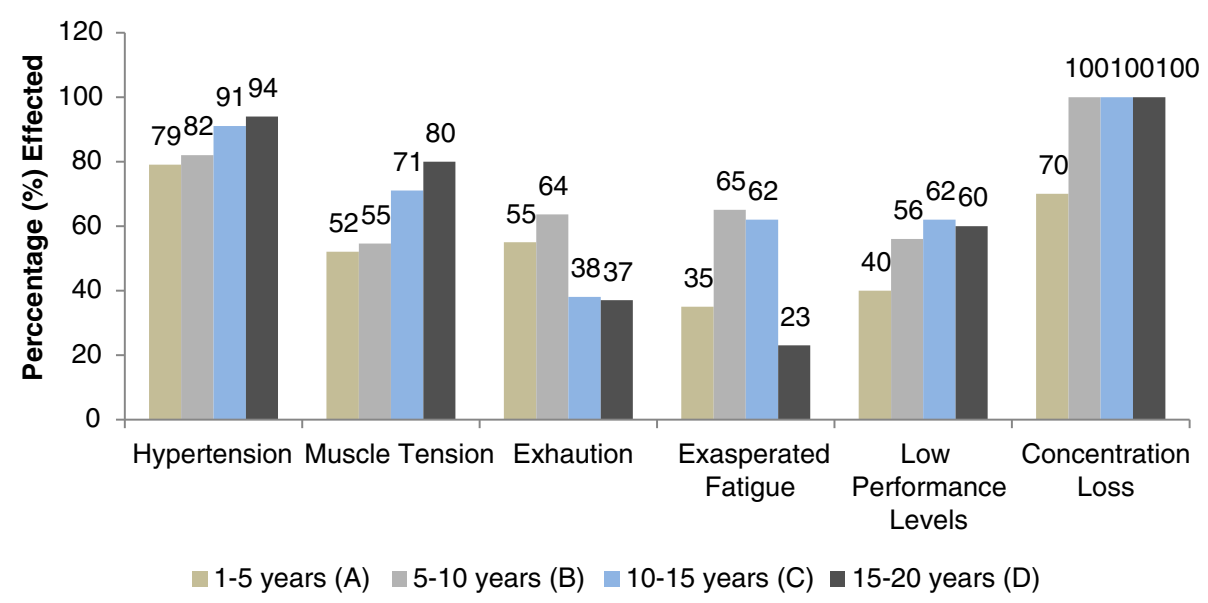

Figure 7 Exposure time wise Physiological effects of noise on traffic wardens. 


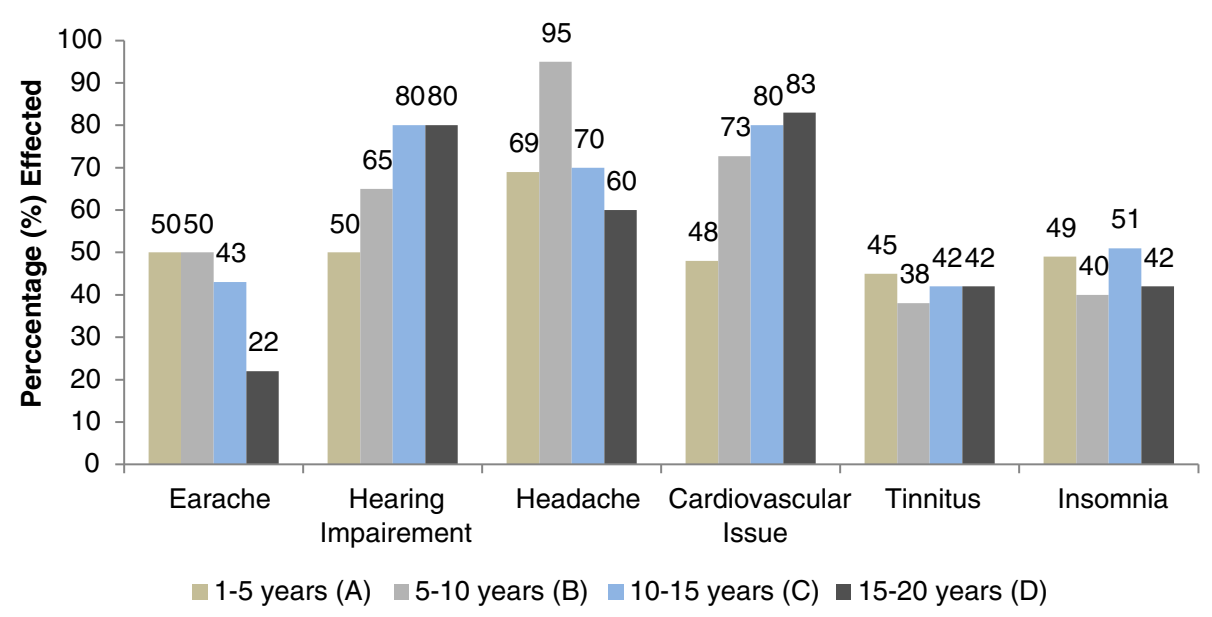

Figure 8 Exposure time wise Physiological effects of noise on traffic wardens.

\section{Earache}

Only 41\% wardens were suffering from earache due to the elevated noise levels. Exposure wise wardens suffering earache; $50 \%, 50 \%, 43 \%$ and $22 \%$ in group A, B, C and D, respectively. A linear relation $\left(\mathrm{R}^{2}=0.786, \mathrm{P}=0.020\right)$ was found between warden's earache reported percentage and

Table 1 Summary of simple regression statistics (exposure-effect relation)

\begin{tabular}{|c|c|c|c|}
\hline $\begin{array}{l}\text { Physio-psychological } \\
\text { effects }\end{array}$ & $\left(R^{2}\right)^{*}$ & P-value* & $\begin{array}{l}\text { Exposure-effect } \\
\text { relation }\end{array}$ \\
\hline Aggravated Depression & 0.978 & 0.033 & Linear \\
\hline Stress & 0.16 & 0.093 & Non-linear \\
\hline Public Conflicts & 0.143 & 0.233 & Non-linear \\
\hline Irritation and Annoyance & 0.327 & 0.099 & Non-linear \\
\hline Behavioral Effects & 0.7 & 0.0388 & Non-linear \\
\hline Speech Interference & 0.4 & 0.349 & Non-linear \\
\hline Hypertension & 0.976 & 0.001 & Linear \\
\hline Muscle Tension & 0.945 & 0.0136 & Linear \\
\hline Exhaustion & 0.609 & 0.0312 & Linear \\
\hline Exasperated Fatigue & 0.06 & 0.21 & Non-linear \\
\hline Low Performance Levels & 0.728 & 0.0396 & Linear \\
\hline Concentration Loss & 0.6 & 0.089 & Linear \\
\hline Earache & 0.786 & 0.020 & Linear \\
\hline Hearing Impairment & 0.896 & 0.0269 & Linear \\
\hline Headache & 0.199 & 0.052 & Non-linear \\
\hline Cardiovascular Issue & 0.827 & 0.049 & Linear \\
\hline Tinnitus & 0.05 & 0.0039 & Constant \\
\hline Insomnia & 0.00588 & 0.025 & Non-linear \\
\hline
\end{tabular}

* $P$-value is the probability of observing a test statistic more extreme than what was observed (if $p<0.05$ then null hypothesis rejected).

${ }^{*} R^{2}$ is a coefficient of determination (measures the how accurate linear model is at predicting i.e. near to unity mean more linear relation). exposure time. Earache decreased with increase in exposure time.

\section{Hearing impairment}

Hearing capability has been impaired of $69 \%$ wardens. Hearing impairment increased as the exposure time increased. The effected personnel percentile variation with the exposure time was as: in group A; $50 \%$, group B; $65 \%$, group C; $80 \%$ and group D; $80 \%$. A linear trend was found between the exposure time and hearing impairment in the wardens $\left(R^{2}=0.896, P=0.0269\right)$.

\section{Headache}

Headache was reported by $74 \%$ traffic wardens. Headache increased and then decreased after ten years time period. Exposure time wise headache; in group A, B, C and D E was $69 \%, 95 \%, 70 \%$ and $60 \%$ respectively. Initial it increased to 10 years after that it decreased. A non linear relation $\left(R^{2}=0.199, P=0.0502\right)$ between exposure time and headache in warden was found.

\section{Cardiovascular issue}

On the whole, $71 \%$ wardens reported cardiovascular issues. Exposure time wise Cardiovascular issues; in group A, B, C and D was $48 \%, 73 \%, 80 \%$ and $83 \%$, respectively. A linear relation $\left(\mathrm{R}^{2}=0.827, \mathrm{P}=0.049\right)$ between exposure time and cardiovascular issues in wardens was found. Heart problem increased as the exposure to noise increased.

\section{Tinnitus}

Ringing ear reported by $42 \%$ wardens only. This percentage was approximately constant $\left(R^{2}=0.05, P=0.0039\right)$ in each group A, B, C and D. 


\section{Insomnia}

About 46\% wardens feel difficulty in sleeping (early wakeup, falling asleep, awakening). Exposure time wise insomnia found in group A, B, C and D was 49\%, 40\%, $51 \%$ and $42 \%$ respectively. A non- linear relation $\left(R^{2}=\right.$ $0.00588, \mathrm{P}=0.025$ ) between exposure and insomnia was established. Summary of the regression test for exposure effect relation is given below in Table 1.

\section{Conclusions}

Noise pollution at selected locations has increased up to dangerous levels. Noise pollution is one of major cause of physiological and psychological deterioration but never gets due attention. Some of the physiopsychological effects showed high percentage of effected traffic wardens initially but decreased as the exposure time increased i.e. behavioral effects, speech interference, exhaustion, exasperated fatigue, ear each and head each. Most of the physio-psychological effects increased as the exposure time increased i.e. hypertension, aggravated depression, muscle tension, low performance levels, concentration loss, hearing impairment and cardiovascular issues. Few effects remained constant as the exposure time increased tinnitus and insomnia, while some effects showed random trends with increase in exposure time i.e. irritation and annoyance, public conflicts and stress. Further investigation of the effects is recommended which showed the random relation with exposure time to reveal reasons.

It can be concluded from the results that physiological and psychological deterioration lead to disturbed social life of traffic wardens. Therefore, efforts should be done to provide a framework in order to reduce duty hours for traffic wardens based on their physiological deterioration due to prolong exposure. Traffic wardens should be equipped with personal protective equipments such as ear plugs to protect their hearing impairment. Most importantly noise reduction techniques should be applied while the road planning, design and construction is in process. Legislation for the standard of vehicles should be in Pakistan. Enforcement of present rules regarding noise could help in noise pollution reduction.

\section{Competing interests}

The authors declare that they have no competing interests.

\section{Authors' contributions}

ST: Data collection, manuscript writing. SA: manuscript proof reading, improvements of results description, presentation of results. IS: psychological effects description/trends evaluation. MBA: manuscript proof reading, improvements of results description, presentation of results. All authors read and approved the final manuscript.

\section{Acknowledgements}

This study has not been completed without the assistance of my undergraduate students; Tayyab Ishtiaq, Sibtain Ali, M. Usman Saleem, Shahzeb Imtiaz, M. Naeem Zaman, Junaid Qaisar, Fawad Humayoon. They assisted author in measuring noise levels and interviewing the wardens.

\section{Author details}

'Department of Environmental Engineering, University of Engineering \& Technology, Taxila, Pakistan. ${ }^{2}$ Department of Psychology, University of Gujrat, Pakistan.

Received: 7 September 2013 Accepted: 8 April 2015

Published online: 16 April 2015

\section{References}

1. ARRB Transport Research. Road surface characteristics and condition: effects on road users, research report ARR314. 1998.

2. FHWA. Highway Traffic Noise Analysis and Abatement. 1995.

3. Pettersson B. Indoor noise and high sound levels - a transcription of the Swedish national board of health and welfare's guidelines. J Sound Vibration. 1997:205(4):475-80.

4. Kupchella, Charles E, Hyland, Margaret C. Living within the system of nature. Environmental Science. 3rd ed. Prentice Hall. 1993: pp. 438.

5. Trombetta Zannin $\mathrm{PH}$, Bunn F. Noise annoyance through railway traffic - a case study. J Environ Health Sci Eng. 2014;12:14.

6. Golmohammadi R, Ghorbani F, Mahjub H, Daneshmehr Z. Study of school noise in the capital city of Tehran-Iran. Iran J Environ Health Sci Eng. 2010;7(4):365-70.

7. Mohammadi G. An investigation of community response to urban traffic noise. Iran J Environ Health Sci Eng. 2009;6(2):137-42.

8. The European Community Green Paper on Future Noise Policy 1996.

9. Berglund B, Institutet K. Proceedings of the 5th International Congress on Noise as a Public Health Problem: 1990; Stockholm, Sweden: Swedish Council for Building Research: Distribution Svensk Byggtjänst. 1990.

10. Van Kempen E, van Kamp I, Fischer P, Davies H, Houthuijs D, Stellato R. Noise exposure and children's blood pressure and heart rate. Occup Environ Med. 2006:63:632-9.

11. Babisch W. Transportation noise and cardiovascular risk: updated review and synthesis of epidemiological studies indicate that the evidence has increased. Noise Health. 2006;8:1-24.

12. Leon Bluhm G, Berglind N, Nordling E, Rosenlund M. Road traffic noise and hypertension. Occup Environ Med. 2007;64:122-6.

13. De Kluizenaar Y, Gansevoort RT, Miedema HM, de Jong PE. Hypertension and road traffic noise exposure. J Occup Environ Med. 2007;49:484-92.

14. Eriksson C, Rosenlund M, Pershagen G, Hilding A, Ostenson CG, Bluhm G. Aircraft noise and incidence of hypertension. Epidemiology. 2007;18:716-21.

15. Eriksson C, Bluhm G, Hilding A, Ostenson CG, Pershagen G. Aircraft noise and incidence of hypertension - gender specific effects. Environ Res. 2010;110:764-72.

16. Belojević GA, Jakovljević BD, Stojanov VJ, Slepcević VZ, Paunović KZ. Night time road-traffic noise and arterial hypertension in an urban population. Hypertens Res. 2008;31:775-81.

17. Jarup L, Babisch W, Houthuijs D, Pershagen G, Katsouyanni K, Cadum E. Hypertension and exposure to noise near airports: the HYENA study. Environ Health Perspect. 2008;116:329-33.

18. Bodin T, Albin M, Ardö J, Stroh E, Ostergren PO, Björk J. Road traffic noise and hypertension: results from a cross-sectional public health survey in southern Sweden. Environ Health. 2009;8:38.

19. Barregard L, Bonde E, Ohrström E. Risk of hypertension from exposure to road traffic noise in a population-based sample. Occup Environ Med. 2009;66:410-5.

20. Barregard L. Traffic noise and hypertension. Environ Res. 2011;111:186-7.

21. Bluhm G, Eriksson C. Cardiovascular effects of environmental noise: research in Sweden. Noise Health. 2011;13:212-6.

22. Lercher $\mathrm{P}$, Botteldooren D, Widmann U, Uhrner U, Kammeringer E. Cardiovascular effects of environmental noise: research in Austria. Noise Health. 2011;13:234-50

23. Passchier-Vermeer W, Passchier WF. Noise exposure and public health. Environ Health Perspect. 2000;108(1):123-31.

24. Babisch W. Cardiovascular effects of noise. In: Nriagu JO, editor. Encyclopedia of Environmental Health. Burlington: Elsevier; 2011. p. 532-42.

25. Akan Z, Yilmaz A, Özdemir O, Selvi Y, Korpinar MA. Noise pollution, psychiatric symptomms and quality of life: Noise problem in the east region of Turkey. Eur Psychiatry. 2012;27(1):436.

26. Gümgüm HB. Noise pollution in the Tigris river basin provinces (Turkey). J Environ. 2012:01(04):142-5.

27. Lercher P, Widdmann U. Association and moderation of self-reported hypotension with traffic noise exposure: a neglected relationship. Noise Health. 2013;15(65):205-16. 